\title{
GCM Study of Synoptic Influences on the Isotope Record in Antarctic Ice Cores
}

\author{
David Noone ${ }^{1}$ and IAN Simmonds ${ }^{2}$ \\ ${ }^{1}$ California Institute of Technology, Pasadena, USA. dcn@gps.caltech.edu \\ 2 School of Earth Science, Melbourne, Australia. simmonds@unimelb.edu.au
}

The stable water isotope record from polar ice cores is often used as a proxy for the condensation temperature at the coring site. Increased isotopic depletion in precipitation during glacial times is interpreted as decreased local temperature following the so-called modern analogue technique (MAT). This assumption is based on wellunderstood physical principles describing the preferential removal of heavy isotopes during condensation. With colder temperatures, greater proportions of the heavy isotopes are removed and increased depletion results. However, such theory applies correctly to individual condensation events rather than climatological mean statistics. Moreover, Antarctic precipitation is characterised by relatively infrequent snowfall episodes that are atypical of the mean state (Noone and Simmonds 1998, Noone et al. 1999). As it is these conditions which are represented in the ice, it becomes important to quantify the possibility for bias in the climate signal away from the mean statistics associated with changes in the frequency and intensity of synoptic activity (Simmonds 1998). Understanding this covariant nature of climate is of great importance for prediction as changes in the behaviour of the climate system, such as the frequency of extreme wet or dry conditions, can lead to societal disaster in climatically marginal areas. State-of-the-art atmospheric general circulation models (GCMs) provide a physically based interpretation of isotopic records in polar ice cores through modeled impacts on simulated proxy records. The Melbourne University GCM includes stable water isotope tracers $\left(\delta^{18} \mathrm{O}\right.$ discussed here) and is used to assess the effects of synoptic variability on the $\delta^{18} \mathrm{O}$-temperature relationship in Antarctica and the reliability of the MAT.
Isotopically based temperature reconstructions typically assume the present day (PD) spatial correlation between $\delta^{18} \mathrm{O}$ and annual mean surface temperature is applicable also to $\delta^{18} \mathrm{O}$ measurements at a single location but representing different epochs. From the control simulation the spatial slope is estimated as $0.78 \% / \mathrm{K}$ using the lowest model level temperature. This compares reasonably well with the observational value of around $0.64 \% / \mathrm{K}$, which is dominated by measurements in the northern hemisphere mid-latitudes. A simulation of the last glacial maximum (LGM) is performed using the CLIMAP surface specification. A temporal $\delta^{18} \mathrm{O}$ temperature slope can be formed from the differences between the LGM and PD results. Figure 1a (front page) shows that the temporal slope and the spatial slope are of similar magnitude over the Antarctic ice sheet but there are also important regional differences. Inland, the temporal slope is smaller while at coastal locations it is larger and shows greater variability. Using the spatial slope and the simulated LGM-PD $\delta^{18} \mathrm{O}$ difference, MAT can be used to generate a (modeled) temperature reconstruction. This is compared directly to the simulated temperature change in figure $1 \mathrm{~b}$ (front page). As the spatial slope is not an accurate estimate of the temporal slope, MAT overestimates the magnitude of the continental temperature change by typically $2 \mathrm{~K}$ although the errors in eastern Dronning Maud Land are $5 \mathrm{~K}$. The locations of the largest errors are broadly upstream of increases in the topography of the ice sheet at the LGM.

Continental precipitation is associated with strong advection from the north. This maritime air is moist and warmer than the mean. As it is only these biased conditions that are represented in ice cores, suc-

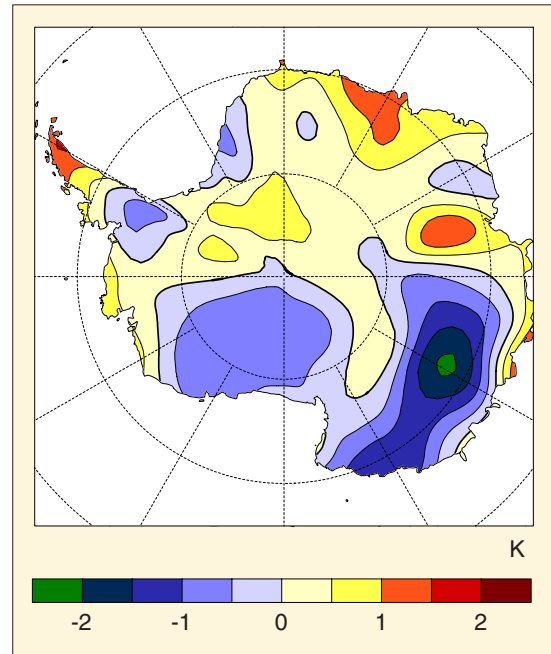

Figure 2: Difference in precipitation temperature bias between last glacial maximum (LGM) and present day (PD).

cessful application of MAT must assume that the amount by which the temperature is above the mean during some epoch (say, LGM) is the same as that of the PD. The difference in the temperature bias between the LGM simulation and PD is shown in Figure 2. Precipitation events are moderately warmer over much of the continent during the LGM. The dominant feature, however, is a decrease in the temperature bias in the Australian sector of around $2 \mathrm{~K}$. This response is of opposite sign to the errors in inland temperature reconstruction and is seen in Figure $1 \mathrm{~b}$ as a reduction in the magnitude of the differences over Wilkes Land. As this reflects a change in the characteristics of the advection in this sector, MAT does not take it into account.

Baroclinic cyclones provide the impetus for advection to inland Antarctica. Figure $3 a$ shows the difference in the cyclone frequency between the LGM and PD. Cyclones are less frequent near the coast south of $60^{\circ} \mathrm{S}$ and more frequent in the $50-60^{\circ} \mathrm{S}$ band. Decreases are also found farther north. Part of the response is associated with changes in the dynamic forcing by the increased LGM topography. However, the primary mechanism results from a requirement for thermodynamic balance and provides heat transport to the polar regions. The net meridional transport by cyclones is proportional to the pressure depth of the cyclone centre 


\section{Paleoclimate Modeling}

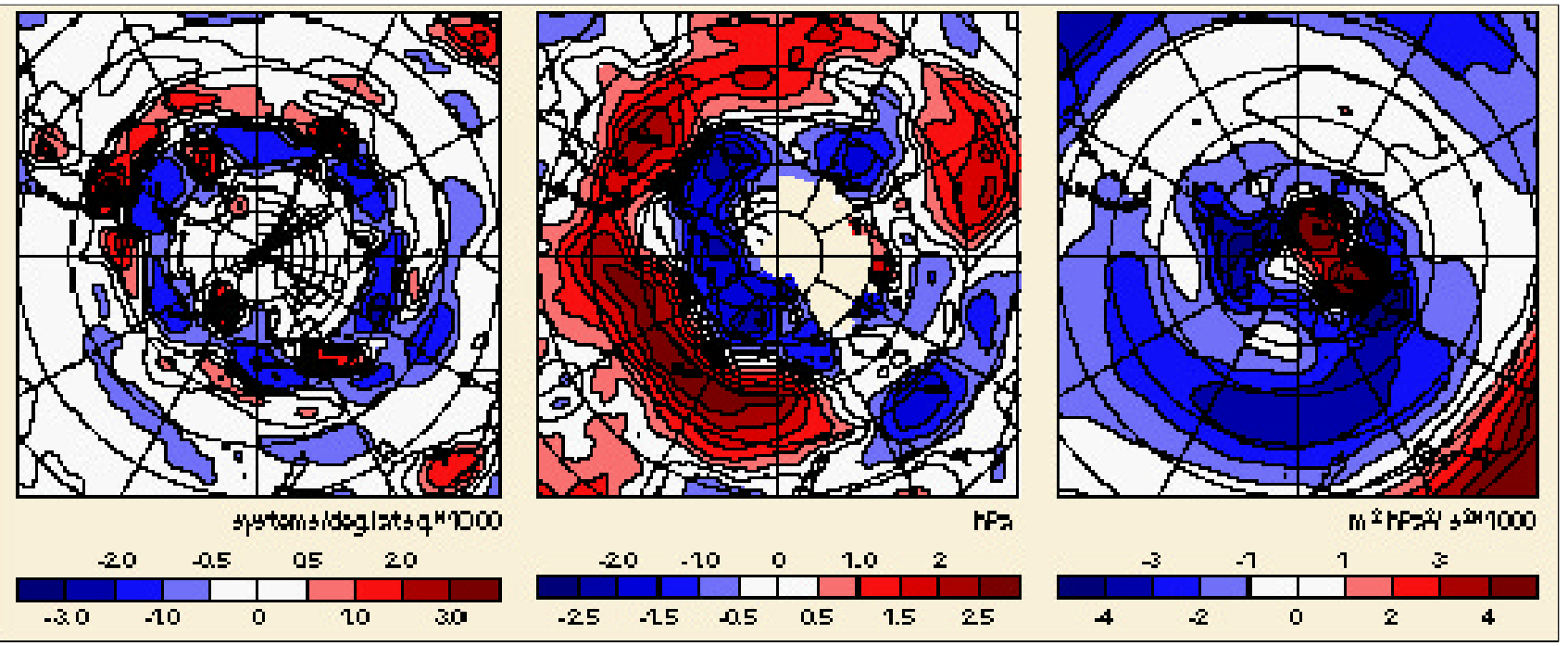

Figure 3: Difference between last glacial maximum (LGM) and present day (PD) cyclone frequency (a), cyclone depth (b) and vertical stability (c).

relative to the background pressure (Simmonds and Keay 2000). Figure $3 \mathrm{~b}$ shows the change in the cyclone depth between the LGM and PD. Cyclones close to the coast and over West Antarctica are less deep while the depth of cyclones to the north of around $60-65^{\circ} \mathrm{S}$ has increased. A most notable exception to this zonally symmetric response is a depth decrease in the Australian sector. Conditions here are more stable during the LGM simulation (Figure $3 c)$ and limit the baroclinic growth rates.

Both fewer cyclones and their reduced depth suggests less net heat transport to the Australian sector while the increased stability constrains the vertical extent to which the advection can ascend the Antarctic topography. Although this explains the negative temperature difference in Figure 2, MAT does not produce the largest error in this region. Rather, these are seen in Fig ure $1 \mathrm{~b}$ over Dronning Maud Land where only small changes in the $\delta^{18} \mathrm{O}$ values are modeled. This is associated with unsubstantial modification of the vertical stability in the southern Atlantic Ocean. The change in isotopic depletion associated with differences in the cyclonic advection is offset by a shift in the latitude from which the moisture is drawn. As such the $\delta^{18} \mathrm{O}$ values do not vary in phase with the temperature changes and the reconstruction errors result.
These results show that while there are significant changes to the condensation history, other factors can oppose the response and allow the isotope signature to be explained on climatological time scales fortuitously by the simple MAT. However, one may not be able to tell a priori if this is the case. Indeed, it remains to be seen if the regional circulation differences identified here are evident in the ice core record. Nonetheless, with GCM simulations to limit the range of climate states possible, an estimate of not only the local or global mean conditions but also the changes in the large-scale circulations and variability could be deduced from ice cores and represents a potentially rewarding pursuit for integrated multi-disciplinary investigations.

\section{REFERENCES}

Noone, D. and I. Simmonds (1998) Implications for the interpretation of ice-core isotope data from analysis of modelled Antarctic precipitation. Ann. Glaciol., 28, 398-402

Noone, D., J. Turner and R. Mulvaney (1999) Atmospheric signals and characteristics of accumulation in Dronning Maud Land, Antarctica. J. Geophys. Res., 104, 19191-19211.

Simmonds, I. (1998) The role of models in understanding climate change. Paleoclimates, 3, 7-23,

Simmonds, I. and K. Keay (2000) Mean Southern. Hemisphere extratropical cyclone behaviour in the 40-year NCEP-NCAR reanalysis. J. Climate, 13, 873-885.

\section{PAQEES NeWS}

\section{A New Name and a New Layout for the PAGES Newsletter}

Over the last few years, the PAGES Newsletter has become an important means of communication among the past global change community. The newsletter benefits from proactive editorial and guest editorial efforts, high quality contributions by a large number of scientists and also the time spent on layout and graphical design. One cosmetic problem has been the long name "PAGES - News of the International Paleoscience Community," even though most people refer to it as "the PAGES Newsletter" or "PAGES News." This latter title has now been made official. In addition, the layout also undergone some changes: more empty space, new fonts and an overall fresher look should make reading an even greater pleasure! The new prominent placement of our website URL on the frontpage points interested readers to another primary means of PAGES communication.

\section{NikLaus Schranz}

PAGES International Project Office, Bern, Switzerland

schranz@pages.unibe.ch 